Tibaldo Zolezzi

Doctor en Teología

\title{
Reino e Iglesia en la enseñanza del Concilio Vaticano II*
}

El presente trabajo es fruto de una larga investigación. En ella, y a partir de la constatación de que la orientación escatológica es un antecedente radical de la enseñanza del Vaticano II (1), se ha querido precisar el modo en que este Concilio ha asumido la problemática del Reino y su relación con la Iglesia.

\section{A MODO DE JUSTIFICACIÓN}

La realización de esta investigación ha estado presidida por cuatro reconocimientos que han servido de presupuestos motivacionales:

1. La significativa presencia de la categoría "Reino" en los documentos del Concilio Vaticano II. Y esto, que constituye una originalidad en comparación con el

* Este artículo es la presentación realizada para el examen doctoral sobre la tesis del mismo nombre y publicada en Anales de la Facultad de Teología. El artículo contiene reelaboraciones en función de las observaciones efectuadas por los profesores examinadores con ocasión de la referida evaluación.

(1) Lo escatológico es un contenido transversal al conjunto de la enseñanza del Concilio y está provisto de una gran riqueza conceptual. De los trabajos referidos a la enseñanza escatológica del Concilio destacamos: A. DOS SANTOS MARTO, Esperança Cristâ e Futuro do Homen. Doutrina Escatológica do Concilio Vaticano II, Dissertatio ad Doctoratum in Facultate Theologiae Pontificiae Universitatis Gregorianae, Roma, 1978, publicada en Porto el año 1987; J. ALFARO, Reflexiones sobre la escatología del Vaticano II, en R. LATOURELLE (Ed.), Vaticano II. Balance y perspectivas. Veinticinco años después (1962-1987), Ediciones Sígueme, Salamanca, 1989, pp. 789-797; C. POZO, Apéndice: La doctrina escatológica del Concilio Vaticano II, en íd., Teología del más allá, B.A.C., Madrid, 1988, pp. 538-578; J. NOEMI, Sobre el enfoque escatológico del Concilio Vaticano II y su vigencia en la teología católica, en Teología y Vida XXIX (1988), pp. 49-59; íd., El mundo, creación y promesa de Dios, San Pablo, Santiago, 1996, pp. 228-264: Mundo e Iglesia en el Concilio Vaticano II. Otras referencias a la escatología del Vaticano II las encontramos en publicaciones que presentan una visión panorámica de la situación de la escatología católica a fines del siglo XX: M. MICHEL, Le retour de l'Eschatologie dans la théologie contemporaine, en Revue des Sciences Religieuses 58 (1984), pp. 180-195; A. TORNOS, La Escatología antes y ahora. Líneas de renovación, en Sal Terrae 75 (1987), pp. 783-792; íd., Escatología, Publicaciones de la Universidad Pontificia de Comillas, Madrid, 1989, especialmente pp. 27-32. 
magisterio conciliar precedente, se da en el contexto de un Concilio que, como sabemos, reflexionó centrado en la Iglesia y su misión en el mundo.

2. El hecho cierto de que el Concilio da espacio a la problemática del Reino y a la de su relación con la Iglesia. Y la intuición de que ella constituye una clave importante de su enseñanza (2). El mismo Concilio ayuda a mirar y comprender dicha relación en referencia a distintos ámbitos: definición de la identidad mistérica, comunional y ministerial de Iglesia, diálogo con el mundo, diálogo ecuménico, impulso misionero.

3. La constatación de que la comprensión de lo que ha dicho el Concilio respecto de la categoría "Reino" y de su relación con la Iglesia no ha sido unívoca. Lo que es fácilmente apreciable en mucha de la literatura teológica que recoge su enseñanza (3).

4. Como contrapartida, la validez del intento de una comprensión global e integradora de las afirmaciones del Concilio. A partir de la sospecha de que lo que él dice acerca de la relación del Reino y de la Iglesia contiene una gran riqueza conceptual: la misma diversidad y aparente contradicción entre sus afirmaciones, no sería entonces más que el reflejo de una comprensión global, recogida en diversos modos de decir.

Es a partir de esta sospecha que se intenta armonizar las diversas afirmaciones conciliares en confrontación con la reflexión teológica del mismo Concilio. Se trata

(2) Lo que es posible constatar desde tres ángulos diferentes: desde el texto mismo de sus documentos, desde la recepción que esta perspectiva ha tenido en la comunidad teológica, desde el proceso de elaboración de los diversos documentos conciliares.

(3) En orden cronológico hacemos referencia a: J. COLLANTES, El Reino de Dios, en C. MORCILlO GONZÁLEZ, Concilio Vaticano II. Constitución sobre la Iglesia, B.A.C., Madrid, 1966, pp. 166-169; J. MÜLLER, Mission und Eschatologie im Konzilsdekret Ad Gentes, en Zeitschrift Missionswissenschaft Religionswissenschaft, 51 (1967), pp. 98-104; B. RIGAUX, El Misterio de la Iglesia a la luz de la Biblia, en G. BARAUNA (Dir.), La Iglesia del Vaticano II. Estudios en torno a la Constitución conciliar sobre la Iglesia, Juan Flors Editor, Barcelona, 1968, pp. 289-307; G. PHILIPS, La Iglesia y su misterio en el Concilio Vaticano II, Herder, Barcelona, 1968, T. I, pp. 119-124; J. -G. PAGE, L'Église, intermédiaire entre le Royaume et le monde, en Laval Théologique et Philosophique, XXIII (1967), pp. 197-243; J.C. HAUGHEY, Church and Kingdom: Ecclesiology in the light of Eschatology, en Theological Studies, 29 (1968), pp. 72-86; H. KÜNG, La Iglesia, Herder, Barcelona, 1969, pp. 55-128; J. LOSADA, Vaticano II: Una Iglesia que intenta entenderse en función del Reino, en Sal Terrae, 66 (1978), pp. 379-389; A. QUIROZ MAGAÑA, Eclesiología en la Teología de la liberación, Ediciones Sígueme, Salamanca, 1983, pp. 117-152; COMISIÓN TEOLÓGICA INTERNACIONAL, Temas selectos de Eclesiología (1984), en íd., Documentos. 1969-1996. Veinticinco años de servicio a la teología de la Iglesia, B.A.C., Madrid, 1998, pp. 327-375; A. DOS SANTOS MARTO, Esperança Cristâ e futuro do homem. Doutrina Escatológica do Concilio Vaticano II, Pontificia Universitas Gregoriana, Porto, 1987, pp. 67-73 y 109-112; J. NOEMI, Sobre el enfoque escatológico del Concilio Vaticano II y su vigencia en la teología católica, en Teología y Vida, XXIX (1988), pp. 49-59; M. L. COOK, Iglesia y reinado de Dios, en Teología y Vida, XXIX (1988), pp. 73-86; S. DIANICH, Iglesia en Misión. Hacia una eclesiología dinámica, Ediciones Sígueme, Salamanca, 1988, pp. 59-64; CH. VON SCHOENBORN, L'Église de la terre, le royaume de Dieu et l'Eglise du ciel. Notes sur Lumen Gentium, Chapitre VII, en P. DE LAUBIER (Ed.), Visages de l'Eglise. Cours d'Ecclesiologie, Editions Universitaires, Fribourg (Suisse), 1989, pp. 169-194; J. RAMOS GUERREIRA, Cristo, Reino y Mundo, tres referencias obligadas para la acción pastoral de la Iglesia, en Salmanticensis, XXXVII/2 (1990), pp. 177-200; J. DUPUIS, L'Église, le Regne de Dieu et les “autres", en Revue de L'Institut Catholique de Paris, 46, 1993, pp. 95-119; L. CHRUPCALA, La Chiesa e il Regno di Dio. Il rapporto definito nella Lumen Gentium, en Antonianum, LXIX/2-3 (1994), pp. 213-230; M. KEHL, La Iglesia. Eclesiología católica, Ediciones Sígueme, Salamanca, 1996, pp. 55-144; CH. MOREROD, Eglise et Royaume de Dieu II: Vatican II, en Nova et Vetera, 75/1 (2000), pp. 39-61. 
entonces de leer el Concilio desde el Concilio mismo: leer e interpretar lo expresamente dicho por el Vaticano II respecto del Reino y su relación con la Iglesia en el contexto amplio de su reflexión teológica. Entonces, más allá de la yuxtaposición como método propio del Concilio (4), será posible reconocer, ya en su misma reflexión, aquella síntesis que integra los elementos que aparentemente yuxtapone.

\section{PRESENCIA E IMPORTANCIA DE LA CUESTIÓN DEL REINO Y LA DE SU RELACIÓN CON LA IGLESIA EN EL TEXTO DE LOS DOCUMENTOS DEL CONCILIO}

Fácilmente es posible constatar la abundante presencia en los textos del Concilio de la imagen del Reino: ella está presente en trece de sus dieciséis documentos (5); Lumen Gentium es donde más encontramos esta imagen (treinta y seis veces) (6), le siguen Gaudium et Spes (doce veces), Ad Gentes (ocho veces), Presbyterorum Ordinis (seis veces), Apostolicam Actuositatem (cinco veces), Perfectae Caritatis (tres veces), Dei Verbum y Unitatis Redintegratio (dos veces), y Sacrosanctum Concilium, Optatam Totius, Gravissimum Educationis, Dignitatis Humanae, e Inter Mirifica (una vez) (7). Se trata, pues, de una presencia significativa que traspasa el conjunto de los documentos del Vaticano II (8). De la lectura de estos textos surge asimismo y con claridad la perspectiva eclesiológica: el Concilio alude a la temática del Reino en cuanto ella dice relación con la Iglesia. Ahora bien, hay párrafos que aportan mayor riqueza para el estudio de esta relación ya que la refieren directamente: textos que expresamente, y en una comprensión más global de su ser y quehacer, indican la condición y finalidad de la Iglesia a la luz del Reino. En razón de esto se estudian los números tres y cinco del primer capítulo de Lumen Gentium, y su número nueve,

(4) Cfr. el importante artículo de H. J. POTTMEYER, Hacia una nueva fase de recepción del Vaticano II. Veinte años de hermenéutica del Concilio, en G. ALBERIGO-J.-P. JOSSUA, La recepción del Vaticano II, Ediciones Cristiandad, Madrid, 1987, pp. 49-67.

(5) Solo en tres documentos del Vaticano II no aparece la imagen del Reino: en los decretos Christus Dominus, sobre el oficio pastoral de los obispos en la Iglesia, y Orientalium Ecclesiarum, sobre las iglesias orientales católicas; y en la declaración Nostra Aetate, sobre las relaciones de la Iglesia con las religiones no cristianas.

(6) En Lumen Gentium la frecuencia con que aparece la imagen del Reino es la siguiente: 13 veces en el capítulo I, que trata del misterio de la Iglesia; 5 veces en el II, que refiere al pueblo de Dios; 1 vez en el capítulo III que trata de la constitución jerárquica de la Iglesia; 10 veces en el capítulo sobre los laicos; 1 vez en el capítulo sobre la universal vocación a la santidad; 4 veces en el capítulo sobre los religiosos; 1 vez en el capítulo VIII, sobre la Virgen María. Llama la atención que la expresión casi no aparece en el capítulo reservado a la índole escatológica de la Iglesia: allí solo aparece una vez $(50,2)$; aunque en un sentido cercano se habla de "reinar con Cristo" $(48,4)$, que refiere al destino último al que están llamados a participar los que acogen el mensaje.

(7) Los números del Concilio en los que más abundantemente aparece la imagen del Reino son los siguientes: L.G. 5 (diez veces); L.G. 36 (seis veces); G.S. 39 (siete veces)

(8) De la lectura inmediata y atenta a los documentos del Vaticano II surgen perspectivas teológicas e indicaciones metodológicas de la mayor importancia. Entre la primeras, la constatación de que en el Concilio la imagen del Reino expresa la intención salvífico-escatológica de Dios que abarca al conjunto de la humanidad, su historia y también la creación; unida al misterio de Cristo, esta misma imagen señala el enraizamiento histórico de la intención salvífica de Dios; e identificada con el Señorío del mismo Cristo, señala la presencia actual al tiempo que la realización futura de esta intención salvífica. Entre las segundas, el recurso permanente a la Sagrada Escritura, la presentación histórico-lineal de la irrupción del reino en el mundo, su irreductibilidad. 
primero de su segundo capítulo; de Gaudium et Spes su primer número y el último de su primera parte, el cuarenta y cinco; del decreto Ad Gentes los números uno, nueve y cuarenta y dos; y de Apostolicam Actuositatem, su número dos.

\section{GÉNESIS DE LAS PRINCIPALES AFIRMACIONES CONCILIARES QUE SE REFIEREN A LA RELACIÓN REINO E IGLESIA}

Al interior del proceso de elaboración de los documentos del Concilio se dio una importante evolución, necesaria de conocer para entender su enseñanza.

Fue sobre todo en el proceso de elaboración de la Constitución dogmática sobre la Iglesia donde la temática del Reino irrumpió en la reflexión conciliar. La inserción de la misma estuvo presidida por la intención de dar una base más bíblica y una comprensión más escatológica al ser y quehacer de la Iglesia (9). En la versión final del esquema se contiene un número especialmente referido a la relación Reino e Iglesia, el número 5. La relatio correspondiente indica que el tema del Reino está en él al servicio de una mejor comprensión de la Iglesia en su misterio, al manifestar la índole a la vez visible y espiritual de la misma, así como su aspecto histórico y escatológico (10). También señala que el vínculo entre ambas realidades pasa por la persona y misión de Cristo y tiene que ver con la fundación, estatuto y misión de la Iglesia. Además indica, al hacer referencia al antiguo número 5 del textus prior (11), que es la relación Cristo/Cabeza - Iglesia/cuerpo suyo en la tierra, lo que constituye a esta en germen e inicio del Reino de los cielos, hacia el que conduce en esperanza. Indicación hermenéutica de gran importancia.

El proceso de elaboración de los números 3 y 9 de Lumen Gentium presenta también algún matiz que da luz para su mejor comprensión. La versión definitiva del número 3, que identifica la Iglesia con el Reino de Cristo, es una versión mitigada respecto de redacciones anteriores (12). La versión definitiva del número 9 parecería

(9) El punto de partida de este proceso lo constituyen afirmaciones más bien marginales contenidas en las dos primeras versiones del esquema De Ecclesia, conocidas y discutidas en el aula conciliar; así como el insistente pedido de los padres conciliares de un mejor tratamiento de la imagen del Reino en su relación con la Iglesia: pues desde una correcta percepción de la enseñanza bíblica respecto del Reino es posible discernir importantes aspectos del ser y quehacer de la misma. Se dio sí una evolución entre la primera y segunda versión del esquema: en la primera la relación Reino-Iglesia se visualizó al modo de una identificación que justificaba una especie de autoafirmación de sí misma; en la segunda, la imagen del Reino, desde una comprensión más escatológica del mismo, ayudaba a ampliar el horizonte de comprensión del misterio de la Iglesia, de su servicio misionero y del estatuto de los creyentes en el mundo. Durante la segunda sesión se insiste en esta orientación escatológica: desde una percepción más escatológica de la noción "Reino" se amplía y funda más solidamente la comprensión de la orientación y condición escatológica de la misma Iglesia; la relación al Reino es percibida como fundamento de una visión más dinámica y perfectible de la misma, al tiempo que desde su relación al Reino es posible refundar su centralidad cristológica y trinitaria, su carácter misionero, su orientación ecuménica y su apertura al mundo.

(10) Cfr. A.S., Vol. III, pars I, p. 173.

(11) Que encontramos en A.S., Vol. II, pars I, pp. 217-218.

(12) Como es sabido, durante la segunda sesión se dio a conocer una nueva propuesta de reordenamiento de todo el documento sobre la Iglesia hecha por Monseñor Suenens (cfr. A.S., Vol. II, pars I, pp. 324-329). En esta propuesta el cardenal belga presentaba un proyecto de 
señalar una suerte de relatividad y transitoriedad de la Iglesia respecto del Reino (13). Ahora bien, y por el contrario, la relatio correspondiente, vincula la relación Iglesia-Reino contenida en este número, con lo que en el esquema se dice acerca de la relación entre la Iglesia peregrinante y la Iglesia celeste (14). Es esta otra importante indicación hermeneútica.

El capítulo VII de Lumen Gentium constituye una primera presentación sistemática, a nivel del magisterio, de la escatología cristiana (15). En él se afirma la tridimensionalidad de la Iglesia: que goza ya de la visión de Dios en sus santos, y, al mismo tiempo, se purifica y peregrina hasta su consumación en la parusía. Las "relaciones" (16) indican que el capítulo se refiere a la índole escatológica de la Iglesia, considerada tanto en su estado glorioso como en su peregrinar hacia su estado final; al tiempo que afirman que la Iglesia terrestre y celeste constituyen un único Pueblo de Dios y un único Cuerpo místico de Cristo. En las alusiones pneumatológicas que encontramos en la versión final del capítulo, y que fueron insistentemente pedidas, reconocemos la sacramentalidad de la Iglesia respecto de la salvación escatológica: por su Espíritu vivificador, Cristo constituyó a su Cuerpo que es la Iglesia como sacramento universal de salvación y por medio de ella une a los hombres a sí y los hace partícipes de su vida gloriosa. A la luz de la unidad tridimensional de la Iglesia, de su carácter peregrino y de su estatuto de sacramento de la salvación escatológica, se comprende la única alusión al Reino que contiene este capítulo: en la vida de los santos Dios nos habla y nos da un signo de su Reino, al cual, por ellos mismos, somos poderosamente atraídos.

La Constitución pastoral sobre la Iglesia en el mundo actual visualiza la misión de la Iglesia a partir de su estatuto y vocación escatológica, comprendida en el contexto de la vocación y también del estatuto escatológico de toda la realidad. Ya, desde la segunda versión del esquema, el punto de partida será una más decidida mirada a la realidad del mundo contemporáneo, que, a modo de inducción, abre todo

redacción en el que prácticamente aparece ya el contenido luego asumido por el número 3 del "textus emendatus" (cfr. A.S., Vol. II, pars I, p. 325). Lo de mayor relevancia para nuestro tema es el hecho de que este texto no incorpora dos elementos presentes en la redacción de Monseñor Suenens: en ella se identificaba sin más a la Iglesia con el Reino ya presente en misterio y se asimilaba la Iglesia con la imagen bíblica del grano de mostaza llamado a crecer. El "textus emendatus" matiza en el sentido de identificar a la Iglesia ahora con el Reino de Cristo y no con el Reino a secas; y no aplica la imagen del grano de mostaza a la Iglesia, pues, en la Escritura, esta imagen dice relación con el Reino y no con la Iglesia.

(13) Es en su segundo párrafo donde aparece, en el contexto de la orientación escatológica del nuevo Pueblo mesiánico, una alusión al Reino de Dios. Si el fin de la Iglesia, entendida ahora más bien en su visibilidad histórica, es dilatar el Reino de Dios, cuyo agente primero y definitivo es el mismo Dios, y si la imagen del Reino consumado se refiere a la creación entera, esta afirmación parecería señalar una suerte de relatividad y transitoriedad de la Iglesia.

(14) De hecho, más tarde, en respuesta a una propuesta de modificación hecha llegar después de la discusión in aula, que pedía una ampliación de la temática escatológica, la comisión correspondiente remitió al capítulo VII del Esquema (cfr. A.S., Vol. III, pars I, pp. 193-194).

(15) Sobre la base de una masiva y recurrente fundamentación bíblica están señaladas en él las notas características de esta escatología: su centralidad cristológica, la tensión dialéctica que la constituye (el ya-pero todavía no), su carácter colectivo e individual, su amplitud cósmica.

(16) La "relación" que acompañó el texto enviado a los padres conciliares antes de la tercera sesión (cfr. A.S., Vol. III, pars I, pp. 351-352) y la que acompañó su presentación en el aula (cfr. A.S., Vol. III, pars I, pp. 375-377). 
el documento; y la reflexión de la misma girará, en los capítulos de su primera parte, en torno a una propuesta sistemática de antropología y cosmología cristiana. Ambas perspectivas señalan una penetrante valoración teológica de la realidad a partir de la comprensión unitaria de los misterios de la creación y la redención. En este contexto lo escatológico, en su carácter de realidad trascendente y englobante, es percibido como aspecto intrínseco y determinante del estatuto y condición de toda la realidad, que no lesiona su autonomía y dignidad, sino que, por el contrario, la funda más solidamente (17). En las dos referencias explícitas al Reino y su relación con la Iglesia que encontramos en la Constitución Pastoral: la de su primer número (18) y la del número 45 (19), el Reino queda comprendido como la realización escatológica del designio amoroso de Dios, en el que Iglesia y mundo quedan concernidos y mutuamente relacionados. Pero la simetría no es perfecta ya que la Iglesia tiene una misión en bien de la familia humana: es sacramento universal de salvación que manifiesta y al mismo tiempo realiza el misterio del amor de Dios al hombre.

Las alusiones al Reino que contiene el Decreto sobre la actividad misionera de la Iglesia (20), permiten visualizar el lugar que ocupan la Iglesia y su tarea misionera en la economía de la salvación, en la vida e historia de la humanidad y en su finalidad escatológica. Su historia redaccional nos ha permitido comprender el Reino como realidad eminentemente teológica y reconocer la identidad e intercambiabi-

(17) La dimensión escatológica de la misma humanidad y de toda la realidad, que Gaudium et Spes desarrolla en los tres primeros capítulos de su primera parte, ha quedado especialmente señalada en su número 39. Al interior de este número se establece una suerte de movimiento pendular que va desde la afirmación del destino escatológico de toda la realidad creada (párrafo primero), a la afirmación de la presencia actual del Reino de Dios en la tierra (tercer párrafo). El vértice se halla en el párrafo segundo en el cual se afirma un estrecho vínculo entre historia y escatología: en esta tierra, como resultado de la preocupación por perfeccionarla, crece el cuerpo de la nueva familia humana, el cual puede de alguna manera anticipar una vislumbre del siglo nuevo. En el contexto de este movimiento pendular adquiere sentido el sedulo distinguendus y el magnopere interest como definidores de la relación existente entre progreso temporal y Reino de Dios. En el párrafo tercero la definición de esta relación alcanza su máxima expresión: en esta tierra el Reino ya está presente en misterio, afirmación que se refiere directamente a todos los buenos frutos de nuestra naturaleza y de nuestro trabajo, que volveremos a encontrar cuando Cristo entregue al Padre el Reino eterno y universal.

(18) En su primer número indica como razón de la íntima unión de la Iglesia con el género humano y su historia su propia raigambre antropológica, su origen trinitario, su peregrinar histórico, su destino escatológico y el anuncio de la salvación, recibido para comunicarlo a todos. Es pues, y a la vez, tanto su realidad histórica como su participación escatológica lo que da razón de la íntima unión de la Iglesia con el género humano y su historia. Así entonces, tanto esta historicidad como el estatuto escatológico de la misma Iglesia se comprenden en el contexto de la historicidad y vocación escatológica del mundo, como queda insinuado a partir de la definición cristiana del concepto "mundo" que nos aporta el párrafo segundo del número 2 de Gaudium et Spes. Ahora bien, a la Iglesia se le ha confiado como tarea el anuncio de la salvación, tiene una misión respecto del género humano: poner a su disposición las fuerzas salvadoras que la misma Iglesia, conducida por el Espíritu Santo, ha recibido de su Fundador, como expresamente lo señala el número 3 del Proemio.

(19) De la misión de la Iglesia en el mundo actual trata el capítulo IV de la primera parte de Gaudium et Spes. En el primer párrafo de su último número, el 45, se afirma cuál sea la pretensión de la Iglesia en su interactuar con el mundo: el advenimiento del Reino de Dios y la salvación de toda la humanidad.

(20) Las que entendemos en el contexto de la sacramentalidad y catolicidad de la Iglesia, como lo exige su primera afirmación (cfr. A.G. 1, 1). 
lidad de las expresiones "Reino de Dios" y "Reino de Cristo" (21). En su actual número 9 ha quedado reflejada la tensión entre una comprensión más escatológica de la acción misionera y otra más eclesiocéntrica, que marcó todo el proceso de elaboración del Decreto (22). La afirmación de que al tiempo de la segunda venida de Cristo la Iglesia será recogida, desde los cuatro vientos, como mies para el Reino de Dios, indicaría no solo el término del tiempo de la misión sino que también la textura de la plenitud escatológica (23).

El primer párrafo del número 2 de Apostolicam Actuositatem sitúa el apostolado de los laicos en el contexto amplio de la única misión de la Iglesia, la que ejercida de diverso modo por todos sus miembros, dice relación con la dilatación del Reino de Cristo por toda la tierra (24). El Reino, como finalidad mayor de la misión

(21) A modo de inclusión, el primero y también el último número de Ad Gentes vinculan estrechamente la Iglesia y su misión con el Reino de Dios y de Cristo. Anunciarlo, establecerlo, difundirlo, preparar sus caminos y orar por su venida, son las expresiones utilizadas para señalar la labor de la Iglesia respecto del Reino. En ellas queda claro tanto la dimensión presente y futura del Reino, como su condición de realidad histórica y trascendente. A este respecto es interesante señalar que a nivel de la votación del textus emendatus se hizo llegar una precisión, aceptada por la comisión redactora, que postulaba la insuficiencia del verbo condere para expresar la relación de la predicación apostólica y el Reino de Dios: esto pues el Reino es una realidad eminentemente teológica (quia Regnum iam a Domino conditum) y, por otra parte, el verbo condere comporta un cierto extrinsecismo (quia condere 'extrinsecismum' sonaret). Asimismo, es de notar, que en el primer número parece distinguirse pero a la vez integrarse el Reino de Dios y el Reino de Cristo, y la relación de la Iglesia con ambos momentos del único plan de salvación: la misión de la Iglesia anuncia e instaura el Reino de Dios difundiendo el Reino de Cristo y preparando los caminos de su venida. Junto a esta integración, y yendo más allá de la misma, es también de notar que, en respuesta a una petición de sustitución de la expresión Reino de Dios por la de Reino de Cristo contenida en el primer "modo" referido al número 42 y hecho llegar en ocasión de las indicaciones que los padres conciliares enviaron al textus emendatus, la comisión redactora respondió negativamente en razón de la identidad de ambas expresiones, identidad que justifica su intercambiabilidad: sed Regnum Christi est etiam Regnum Dei.

(22) En este sentido aparece ya en el párrafo segundo del primer número de Ad Gentes una indicación de la mayor importancia: la obra de salvación y renovación de todas las creaturas, a la cual la Iglesia se siente urgentemente llamada, tiene por finalidad que todo sea instaurado en Cristo y en Él los hombres constituyan una familia y un único pueblo de Dios. Es la finalidad escatológica a la cual tiende la actividad misionera de la Iglesia. Esta actividad, que discurre entre la primera venida del Señor y la segunda, como lo afirma el número 9 de Ad Gentes, y que se ejerce como manifestación del propósito salvador de Dios haciendo presente a Cristo, se articula como restituir a Él todas las cosas, purificando, elevando y consumando cuanto de bueno, de verdad y de gracia se encuentra sembrado ya en el corazón y en la mente de los hombres y de las culturas. Ahora bien, esta presencia sanante y elevante de Cristo, que encamina todas las cosas a la plenitud escatológica, se visualiza y se expresa como dilatación, crecimiento y edificación de la misma Iglesia que es el Pueblo de Dios, Cuerpo místico y templo espiritual.

(23) La verdad es que la cuestión respecto del estatuto de la Iglesia en el Reino escatológico es algo que el Concilio deja abierta. Ahora bien, en diversos contextos el Concilio señala la estructura eclesial de la consumación escatológica. Así, por ejemplo, en L.G. 2 se habla de que el cumplimiento escatológico del propósito divino consistirá en la congregación de todos los justos en una Iglesia universal en la casa del Padre. En S.C. 8 y L.G. 51, 2 se habla de la liturgia de la gloria consumada: unidos a Cristo, a través del cual el Padre comunica eternamente su amor a los hombres, y en torno a Él, como Iglesia, cantaremos eternamente su alabanza. En G.S. 32, 5 se habla del día de la consumación como aquel en el cual los hombres, salvados por la gracia, como familia amada de Dios y de Cristo hermano, darán a Dios gloria perfecta.

(24) Una primera constatación importante dice relación con el hecho de que se trata precisamente del Reino de Cristo. Esto visualiza la misión de la Iglesia en el contexto de la presencia y crecimiento del Reino en la historia de la humanidad; al tiempo que, como ya sabemos, implícitamente la refiere al cumplimiento escatológico de este Reino. 
apostólica de la Iglesia, incluye todas las dimensiones de este apostolado, sus diversos fines inmediatos (25). Esto queda mejor comprendido a la luz de la evolución que se dio a lo largo del proceso de elaboración del Decreto, pues en un primer momento pareció identificarse la promoción del Reino casi exclusivamente con la dimensión religiosa o espiritual de la misión de la Iglesia (26).

\section{INTERPRETACIÓN DE LAS PRINCIPALES AFIRMACIONES QUE SE REFIEREN AL REINO Y SU RELACIÓN CON LA IGLESIA A LA LUZ DE LA CRISTOLOGÍA Y LA ANTROPOLOGÍA DEL CONCILIO}

El paso siguiente en el desarrollo de la investigación es el intento de interpretar las principales afirmaciones que refieren al Reino y su relación con la Iglesia a la luz de dos núcleos articuladores del conjunto del magisterio del Vaticano II: su cristología y su antropología. La confrontación con ambas temáticas, y la comprensión de las mismas como una importante clave de lectura e interpretación de las afirmaciones referidas al Reino y a la Iglesia, viene exigida por el mismo recorrido realizado hasta ahora: brota como necesidad ineludible de la lectura atenta de los textos, de los aciertos y carencias de la literatura secundaria aludida, y, sobre todo, del más preciso significado que han adquirido las afirmaciones conciliares a la luz del proceso de elaboración de los distintos documentos del Vaticano II.

Primero se relaciona el Reino, la Iglesia y, consecuentemente, también el mundo, con la soberanía gloriosa de Cristo resucitado.

En la actual fase de la historia de la salvación, el Reino de Dios está presente y opera a través de la soberanía de Cristo resucitado y glorificado (L.G. 5,2; 36,1;

(25) Se trata del para qué fundamental del ser de la Iglesia que engloba los diversos fines inmediatos de su tarea apostólica. Esto está claramente indicado con la mención de los otros elementos que forman parte de esta definición programática que comentamos: la glorificación de Dios, la redención de todos los hombres y el ordenamiento de todas las cosas hacia Cristo.

(26) En un primer momento pareció identificarse la promoción del Reino casi exclusivamente con la dimensión religiosa o espiritual de la misión de la Iglesia: es lo que sugiere el hecho de que en los esquemas de la fase preparatoria el apartado referido al primer fin de la misión de la Iglesia llevase por título De apostolatu laicorum ad Regnum Christi directe provehendum (cfr. Schema Decreti De Apostolatu Laicorum, A.S., Vol. III, pars IV, pp. 669-710). Ya en la redacción del esquema conocida como textus prior se cambia el título del apartado que refiere al primer fin de la misión apostólica: el ahora número 10 se denomina De hominum conversione et progresu ad Deum (cfr. A.S., Vol. III, pars III, p. 373). La relatio explica que el cambio se debe a la intención de expresar mejor el objeto inmediato de la primera especie de apostolado: la conversión y acercamiento a Dios (cfr. Ibídem, p. 389). Al señalar aquello a lo que se refiere el contenido del número, la misma relatio, afirma que se trata del apostolado religioso, espiritual (cfr. Ibídem, p. 400). Sin embargo, aunque una enmienda ya preveía el cambio, aun a nivel del textus prior, este mismo número 10 comienza con un párrafo que parece todavía insinuar la identificación del Reino con este primer fin de la misión de la Iglesia: Caritas Christi urget nos (2 Cor. 5, 14) ut omnibus hominibus imprimis bonum fidei gratiaeque donum provideatur, iuxta illud Christi: Quaerite ergo primum regnum Dei et iustitiam eius (Mt. 6, 33)" (A.S., Vol. III, p. 373). En el textus emendatus, el ahora número 6 (De apostolatu ad homines evangelizandos et santificandos) no incluye la cita de Mt. 6, 33 (cfr. A.S., Vol. IV, pars II, pp. 319-320). Lo llamativo es que sí incluye una expresión similar el número 7 (De ordine rerum temporalium christiane instaurando) al hablar de la obligación de los laicos de actuar como creyentes y ciudadanos responsables en el orden temporal y ubique et in omnibus iustitiam regni Dei quaerere (cfr. Ibídem, pp. 320-322). 
38,1). En la Iglesia y en el mundo se da una presencia anticipada y dinámica del Reino, que refiere en todo momento a la condición resucitada y señorial de Cristo (L.G. 3; G.S. 39,3). Cristo ejerce su dominio salvífico por la acción del Espíritu Santo (L.G. 48; G.S. 38); y su Soberanía es pascual: se establece como derrota de los poderes de este mundo, y lleva a la misma creación al cumplimiento de su más original posibilidad (L.G. 5,1; 36,1) (27).

Este Señorío de Cristo se comporta como clave escatológica del ser de la Iglesia y de su misión en el mundo. La afirmación conciliar que más identifica al Reino con la Iglesia: "Ecclesia, seu regnum Christi iam praesens in mysterio" (L.G. 3), al ser leída en el contexto del capítulo I de Lumen Gentium, adquiere una significación más precisa: señala sintéticamente el fundamento teológico del ser eclesial, que encuentra su origen en el designio salvífico de Dios (L.G. 2), manifestado en las misiones trinitarias (L.G. 3 y 4), y en la gracia que Cristo, Señor y Cabeza, derrama sobre ella (L.G. 7). A la luz de este fundamento trinitario y cristológico la relación de la Iglesia con el Reino adquiere connotaciones propias: remite a un cumplimiento pleno del Reino que dice relación con la creación entera, y al cual la Iglesia sirve a través de su propio crecimiento y de su misión en el mundo. Para mejor comprender esto nos detenemos en el número 7 de Lumen Gentium (28), en el cual el Concilio desarrolla la relación entre la soberanía actual de Cristo y la Iglesia: aquí esta relación queda expresada en la imagen de la Iglesia como cuerpo místico de Cristo y en el vínculo que la une a Él como a su Cabeza (29).

El Reino actual de Cristo se comporta también como clave escatológica de la densidad del mundo y de la historia. La segunda afirmación del Concilio que indica la presencia actual del Reino en el mundo: "His in terris Regnum iam in mysterio

(27) Esta concentración cristológica de la soberanía salvífica de Dios incluye el carácter actual y remoto a la vez del cumplimiento del Reino (P.O. 2, 5; G.S. 39, 3) y la participación en él de toda la realidad creada (L.G. 36, 1; G.S. 39, 3).

(28) El actual número 7 de Lumen Gentium constituye una especie de síntesis final de un desarrollo doctrinal que en las versiones anteriores del esquema era más amplio y determinante para el conjunto de la Constitución sobre la Iglesia. En la primera versión del Esquema, elaborada por la Comisión doctrinal preparatoria y presentada a los Padres en el contexto de la primera Sesión del Concilio, se dedicaba amplio espacio a la figura del Cuerpo místico: se hacía mención a ella en los números 4, 5, 6 y 7 del primer capítulo (cfr. A.S., Vol. I, pars IV, pp. 14-15 y notas pp. 16-17) y en los tres números del capítulo segundo (cfr. A.S., Vol. I, pars IV, pp. 18-19 y notas pp. 1922). Ya en la segunda versión, en la que empieza a asumir la función de hilo conductor la figura bíblica Pueblo de Dios, la figura de la Iglesia Cuerpo de Cristo se incorpora, como número 5, en el nuevo capítulo primero De Ecclesiae Mysterio (cfr. A.S., Vol. II, pars I, pp. 217-218 y notas pp. 224-225). En la versión del "textus emendatus", junto con un reordenamiento interior, el número dedicado al Cuerpo Místico encuentra su definitivo lugar dentro del mismo capítulo primero: ahora como séptimo número luego del tema del Reino y de las diversas imágenes de la Iglesia a las que el Concilio alude (cfr. A.S., Vol. III, pars I, pp. 164-167 y notas p. 169). Con algunas precisiones, a partir de los "modi" propuestos por los Padres conciliares y aprobados por la Comisión doctrinal (A.S., Vol. III, pars VI, pp. 81 y 82), se llega a la versión final de este número 7 de la Constitutio dogmatica de Ecclesia (cfr. A.S., Vol. III, pars VIII, pp. 787-789, texto y notas).

(29) En su ocho párrafos, este importante número de la Constitución dogmática, describe la relación de Cristo con la Iglesia asumiendo la doble afirmación de San Pablo: la Iglesia es el cuerpo de Cristo y Cristo es la Cabeza de este cuerpo. Así hace suya, en una presentación integrada, las perspectivas de 1Corintios-Romanos, por una parte, y de Colosenses-Efesios, por otra: la Iglesia es el cuerpo formado por muchos creyentes que se unen por Cristo y en Cristo, y es también el cuerpo del mismo Cristo. 
adest" (G.S. 39,3), se refiere a un estar presente del Reino que dice relación con "todos los buenos frutos de la naturaleza y de nuestro esfuerzo". Ahora bien, el mismo párrafo tercero del número 39 de Gaudium et Spes señala una condición decisiva para comprender estos frutos como semillas del Reino eterno y universal: "posquam in Spiritu Domini et iuxta eius mandatum in terris propagaverimus". Esta afirmación vincula nuestro texto con el número 38 inmediatamente anterior, que se refiere a la perfección que la actividad humana encuentra en el misterio pascual de Cristo (30), y que, en ese contexto, alude a la temática de su relación con el Reino de los cielos: en la resurrección los valores de este mundo alcanzan su sentido más profundo, aparecen como semillas del Reino definitivo (31).

La referencia a Cristo impone mirar y comprender el vínculo que existe entre el Reino y la Iglesia a la luz de la relación que ambos establecen con el mundo. La perspectiva antropológica del Reino la encontramos en la relación entre Cristo y el hombre que enseña Gaudium et Spes. Y a su luz entendemos la triple afirmación de Lumen Gentium 5, 2: la Iglesia constituye en la tierra el germen y el comienzo del Reino de Cristo y de Dios, y junto con anhelar su consumación, y esperar y desear ardientemente unirse con su Rey en la gloria, tiene la misión de anunciarlo e instaurarlo en toda la humanidad.

En la Constitución pastoral encontramos una reflexión antropológica que busca comprender al hombre y todas las cosas desde su esencial relación a Cristo (32). En ello el mismo Reino queda señalado: se da allí donde se realiza el encuentro hombre-Cristo, en el que se manifiesta el amor de Dios al hombre. La comprensión del hombre a la luz de Cristo significa en definitiva reconocer su condición de creatura relativa, en dependencia y apertura a Dios, y salvada en Cristo. Se trata de una palabra sobre el hombre a la luz de lo que significa para Dios, que permite descubrir su misterio profundo y reconocer las expresiones de este misterio en el ser y hacer humanos: el hombre es imagen de Dios, capaz de Dios, habitado por Dios y llamado a adherirse a Él con todo su ser; en esto radica la razón más alta de su dignidad personal y de su bondad (33). Se trata también de una palabra sobre el

(30) Cristo resucitado, al cual le ha sido dada toda potestad en el cielo y en la tierra, obra ya por la virtud de su Espíritu: despertando el anhelo del siglo futuro, alentando, purificando y robusteciendo los propósitos con los que la familia humana intenta hacer más llevadera su propia vida y someter la tierra a ese fin, llamando a unos a dar testimonio del anhelo de las moradas celestes, a otros a que se dediquen al servicio terreno de los hombres y por este ministerio preparen el material del reino celestial, liberando a todos para que se proyecten hacia las realidades futuras.

(31) El acontecimiento de la resurrección de Cristo, y el don del Espíritu que le es inseparable, han hecho presente en el mundo el Reino de Dios y han dado así comienzo a la renovación definitiva de la humanidad. Es entonces necesario hacer una doble afirmación: por una parte, decir que se da una continuidad entre el presente y el futuro, entre la actividad humana y el Reino de Dios, en el sentido de que los esfuerzos humanos preparan el material del Reino de los cielos; y, por otra, decir también que se da una radical novedad en la medida en que el hacer humano y sus frutos son anticipación del Reino futuro solo si son vividos como expresión del Señorío de Cristo, "fuerza que viene de lo alto", y si se orientan a un cumplimiento pleno, que advendrá solo a través de la transfiguración escatológica de toda la realidad.

(32) Es esta la perspectiva central de la comprensión del hombre que el Concilio ofrece en Gaudium et Spes como enseñanza y base del diálogo de la Iglesia con el mundo.

(33) Lo es, en primer lugar, como creatura (12) corpóreo-espiritual, centro y cima de todos los bienes de la tierra (14), dotado de inteligencia (15), conciencia (16) y libertad (17), y creado por Dios para un destino feliz situado más allá de las fronteras de la miseria terrestre (18). Lo es también 
hombre que indica que el cumplimiento de lo que significa para Dios solo es posible por la autodonación personal y libre del mismo Dios, que, por Cristo y en el Espíritu, se nos comunica como amor salvador. El advenimiento del Reino se da allí donde Dios es acogido en la comunicación de su amor. Amor que hace posible la comunión con Él y, en torno a Él, de toda la realidad.

El talante cristológico de la antropología, tal como el Concilio lo enseña, remite a la Iglesia, se concretiza en ella y alcanza en ella una plenitud (34). La Iglesia es germen y comienzo del Reino en cuanto la relación hombre-Cristo se da en ella y en ella remite a un cumplimiento pleno. La comprensión de la eclesialidad del Reino (35) lleva a la comprensión de la necesidad y catolicidad de la Iglesia (36), misterio de comunión

en su carácter relacional comunitario: como imagen y semejanza de Dios el hombre encuentra su propia plenitud en la entrega de sí a los demás (24), la unidad de origen y destino de todos los hombres establece una igualdad fundamental entre ellos y señala la esencial vocación a la comunión que constituye al hombre (29); el mismo creador ha puesto en él, en su naturaleza espiritual y moral, las leyes que regulan la vida social y le orienta con el mandamiento del amor (29). Lo es, finalmente, en cuanto ha sido constituido señor de la creación visible para gobernarla y usarla glorificando a Dios: por eso el trabajo humano tiene un valor de colaboración (34) y una ordenación que, poniendo al mismo hombre en su centro (35), contribuye a que se cumplan los designios de Dios en la historia; esta valoración y ordenación de la actividad humana no lesiona ni disminuye su autonomía (humani generis victorias signum esse magnitudinis Dei et fructus ineffabilis Ipsius consilii), por el contrario, ella tiene su raíz en la voluntad del mismo creador que ha dotado todas las cosas de consistencia, verdad y bondad propias, y de propias leyes y valores que el hombre debe descubrir, emplear y ordenar poco a poco (36).

(34) Así lo establecen explícitamente los capítulos de la primera parte de Gaudium et Spes: la perfección de la dignidad humana, de la comunión fraterna y de la actividad transformadora de la realidad se alcanza solo a la luz del Evangelio que se le ha confiado a la Iglesia y por la fuerza del Espíritu que alienta, en la Iglesia y siempre en relación con ella, la configuración con Cristo y el cumplimiento de la ley nueva del amor (cfr. G.S. 22, 4; 32, 4-5; 38, 2). Es como Iglesia que el hombre cumple su vocación de apertura a Dios y a los hermanos.

(35) El Reino, cuya naturaleza es la comunión de todos los seres humanos entre sí y con Dios (R.M. 15) tiene siempre como soporte un sujeto social. El Concilio entiende esta eclesialidad del Reino en un sentido amplio y la expresa en la vinculación que establece entre Reino y comunión. En G.S. 39 se habla de modo explícito, aunque también en forma indirecta, de esta vinculación: en su segundo párrafo afirma que el progreso temporal en cuanto (inquantum) puede contribuir a mejor ordenar la sociedad humana, interesa en gran medida (magnopere interest) al Reino de Dios; en su tercer párrafo indica que entre los bienes que volveremos a encontrar (denuo inveniemus), cuando Cristo entregue al Padre el Reino eterno y universal, se halla la "comunión fraterna", de la que el Concilio ha hablado ya, y en un sentido histórico y escatológico, en el capítulo II de la primera parte de la Constitución Pastoral. En el mismo párrafo tercero de este número 39 que comentamos, se contiene aquella "definición" del Reino tomada del prefacio de la Misa de la festividad de Cristo Rey y Señor del universo: los términos en ella empleados indican, a un tiempo, la dimensión teológica, salvífica y comunional del Reino. En mayor profundidad reconocemos esta vinculación a la luz de teología trinitaria que orienta decisivamente la enseñanza del Vaticano II y que hemos mencionado ya en el capítulo I de esta investigación (cfr. 2. 1. 1.): el Reino como manifestación histórica del misterio del amor eterno de Dios Padre, Hijo y Espíritu Santo, que se expresa como acción trinitario-salvífica a favor de la creación, la que está llamada a participar de la comunión de la vida divina.

(36) Como sabemos el capítulo II de Lumen Gentium está construido sobre una comprensión universal del misterio de la salvación y su correspondiente vinculación al misterio de Cristo y de la Iglesia, que fundamenta tanto el reconocimiento de la necesidad de la Iglesia (L.G. 14, 1), como su carácter misionero (L.G. 17). Ahora bien, si la comprensión eclesial de la salvación funda la afirmación de la necesidad de la Iglesia, al mismo tiempo define la comprensión de su catolicidad. El número 13 de Lumen Gentium, luego de fundar la catolicidad del único pueblo de Dios en el designio de la voluntad de Dios (manifestado en la misma creación de una sola naturaleza humana y en la congregación de los que estaban dispersos) y en la misión del Hijo y 
universal (37), que anticipa el destino último de la humanidad y la historia, pues vive ya, en su presente, la comunión escatológica (38). La Iglesia peregrina hacia el Reino en cuanto la relación hombre-Cristo constituye una clave, un modelo y también la meta de lo que ella está llamada a ser. La comprensión antropológica de la presencia actual y de la consumación escatológica del Reino implica la comprensión de la relatividad histórica de la Iglesia: la configuración con Cristo es el origen histórico y existencial de la Iglesia y, al mismo tiempo, el deber ser de su existencia y también su futuro (39). La Iglesia anuncia e instaura el reino de Cristo y de Dios en cuanto ella sirve a la relación hombre-Cristo, ofreciendo al mundo su propia relación a Cristo. La sacramentalidad del

del Espíritu Santo (párrafo primero), en su segundo párrafo vincula esta catolicidad con el Reino, a la luz del cual esta catolicidad se comprende en una amplitud étnico-geográfica y en perspectiva unitaria, inclusiva y recapituladora: "Omnibus itaque gentibus terrae inest unus Populus Dei, cum ex omnibus gentibus mutuetur suos cives, Regni quidem indolis non terrestris, sed coelestis. Cuncti enim per orbem sparsi fideles cum ceteris in Spiritu Sancto communicant, et sic "qui Romae sedet, Indos scit membrum suum esse". Cum autem Regnum Christi de hoc mundo non sit (cf. Io 18, 36), ideo Ecclesia seu Populus Dei, hoc Regnum inducens, nihil bono temporali cuiusvis populi subtrahit, sed e contra facultates et copias moresque populorum, quantum bona sunt, fovet et assumit, assumendo vero purificat, roborat et elevat. Memor est enim se cum illo Rege colligere debere, Cui gentes in hereditatem datae sunt (cf. Ps 2, 8), et in Cuius civitatem dona et munera adducunt (cf. Ps 71 (72), 10; Is 60, 4-7; Apoc 21, 24). Hic universalitatis character, qui Populum Dei condecorat, ipsius Domini donum est, quo catholica Ecclesia efficaciter et perpetuo tendit ad recapitulandam totam humanitatem cum omnibus bonis eius, sub Capite Christo, in unitate Spiritus Eius" (L.G. 13, 2). A esta unidad católica, que se expresa en la diversidad y comunicación de bienes que se da al interior del mismo Pueblo de Dios (párrafo tercero), son llamados todos los hombres, y a ella pertenecen o están ordenados de diverso modo (párrafo cuarto).

(37) El reconocimiento de la esencial eclesialidad de la gracia y de su acción más allá de las fronteras de la Iglesia visible conduce a una nueva comprensión de la Iglesia, que el Concilio tematizó en la noción de la misma como misterio de comunión universal, pueblo de Dios al que están llamados todos los hombres (L.G. 13,4) cuya vocación es congregar a todos los justos hasta constituir una "ecclesia universalis" (L.G. 2). Surge así una renovada y más amplia comprensión de la Iglesia como misterio de comunión que robustece y completa la unión de la familia humana y anticipa así, ya en este tiempo, la comunión escatológica a la que está llamada la misma humanidad.

(38) La Iglesia, siendo verdadera comunión universal y actuando en conformidad a ello, anticipa el destino último y definitivo de la humanidad y la historia pues vive ya en su presente la comunión escatológica que, siendo futura, ya ha comenzado, y se da en ella en tensión hacia su cumplimiento pleno. La comprensión de la Iglesia una en tres estados diversos de desarrollo, que nos ofrece el capítulo VII de Lumen Gentium ( $\mathrm{n}^{\circ} 49$ ) orienta en un sentido de universalismo transhistórico y escatológico la misma comunión que la constituye. En cuanto comunión de los santos la misma Iglesia queda señalada como verdadero germen y segurísimo comienzo del futuro de la humanidad, hasta el día de su consumación definitiva, día de la plena participación de toda la creación en la comunión de la vida trinitaria.

(39) El Reino, en la misma comprensión antropológica de su presencia actual y de su consumación escatológica, se establece como futuro de la Iglesia. La comunidad con Cristo y en Cristo que es el centro vital de la Iglesia (la expresión es de Pannemberg, Teología y Reino de Dios, Ediciones Sígueme, Salamanca, 1974, especialmente pp. 41-84), es en sí misma una realidad dinámica, omniabarcante y escatológica, por eso, al tiempo que funda la Iglesia constituye también su futuro: la configuración del hombre y de todos los hombres con Cristo y entre ellos, futuro "ya comenzado" y al mismo tiempo "todavía no cumplido" de la misma humanidad y de la creación entera, es el origen histórico y existencial de la Iglesia y al mismo tiempo el deber ser de su existencia y también su futuro. Los primeros números de Lumen Gentium ubican el misterio de la Iglesia en el contexto de las misiones del Hijo y del Espíritu Santo y su correspondiente relación con el designio del Padre de hacernos participar de la vida divina. Este designio, que se realiza a través de la unión con Cristo por la vivificación del Espíritu, se expresa en la Iglesia y, como tal, tiene una realización histórica y un cumplimiento escatológico. 
Reino (40) determina la comprensión de la sacramentalidad de la misma Iglesia (41): ella es signo e instrumento de la comunicación de la gracia a partir de su condición de actualización de la comunión escatológica (42), de la que vive y a la que sirve (43).

(40) En diversos contextos el concilio señala la estructura sacramental del acontecimiento de la salvación (D.V. 2; 4,1; S.C. 5; 6). En la encarnación del Hijo de Dios la comunicación de la gracia asume la realidad creada y la historia humana (A.G. 3; cfr. también G.S. 22, 2; 32, 2; 38, 1 y 45, 2). De ello deriva la posibilidad de significación e instrumentalidad de las realidades humanas en orden a la comunicación de la vida divina y de la salvación de los hombres (lo que se verifica en forma eminente en el mismo Cristo: "Ipsius namque humanitas, in unitate personae Verbi, fuit instrumentum nostrae salutis" (S.C. 5, 1); y desde Cristo, las realidades humanas, sanadas y elevadas, adquieren calidad sacramental), al tiempo que funda la condición sacramental de la misma Iglesia (L.G. 8, 1). La gracia de Cristo es gracia de encarnación y por lo mismo tiene una estructura sacramental y eclesial.

(41) El Concilio define a la Iglesia como "sacramento universal de salvación" (L.G. 48, 2; G.S. 45, 1; A.G. 1, 1). La Iglesia es en Cristo como un sacramento, o sea signo e instrumento de la unión íntima con Dios y de la unidad de todo el género humano. Esta es traducción de la definición inicial y programática que el Concilio aplica a la Iglesia: "Ecclesia sit in Christo veluti sacramentum seu signum et instrumentum intimae cum Deo unionis totiusque generis humani unitatis"(L.G. 1). El "in Christo" señala el origen y fundamento de la sacramentalidad de la Iglesia, a la vez que la razón de su eficacia como actualización en ella de la presencia del mismo Cristo y su permanente referencia y subordinación a esa presencia. El "veluti sacramentum" indica tanto la comprensión analógica de la sacramentalidad de la Iglesia respecto de la de Cristo como respecto de las siete acciones sacramentales de la Iglesia, en relación a las cuales habría que decir que el concepto "sacramento" se verifica en la Iglesia de un modo análogo y eminente. La expresión "signum et instrumentum" corresponde a la noción clásica utilizada para explicar la función propia de los sacramentos como "formas visibles de la gracia invisible" (DS 1639) que "contienen lo que significan" (DS 1606). Finalmente, es oportuno destacar que el efecto propio del sacramento eclesial comprende, en una inseparable unidad, una dimensión vertical (la unión del hombre con Dios) y otra horizontal (la unidad del género humano).

(42) En la comprensión de la sacramentalidad de la Iglesia se expresa la triple tensión estructural que la constituye en una compleja unidad: su condición de realidad a la vez humana y divina, visible y espiritual, histórica y escatológica (L.G. 8, 1). La sacramentalidad de la Iglesia, en cuanto comunidad visible de fe, esperanza y caridad, mediante la cual el mismo Cristo sigue comunicando la verdad y la gracia a todos, aparece en la historia como expresión de su configuración con Cristo: su sacramentalidad deriva de la sacramentalidad de Cristo. El Concilio presenta el nacimiento de la Iglesia-sacramento como un momento intrínseco y constitutivo del acto redentor de Cristo en la cruz (S.C. 5, 2: "Nam de latere Christi in cruce dormientis ortum est totius Ecclesiae mirabile sacramentum") llamado a perpetuarse en la historia a través de la acción sacramental de la misma Iglesia (cfr. S.C. 6). La sacramentalidad de la Iglesia aparece también como fruto de la vivificación por el Espíritu: a través del envío de su Espíritu, Cristo glorificado constituye a la Iglesia como sacramento, por medio del cual continúa su obra en el mundo: "Christus quidem exaltatus a terra omnes traxit ad seipsum (cf. Io 12, 32 gr.); resurgens ex mortuis (cf. Rom 6, 9) Spiritum suum vivificantem in discipulos immisit et per eum Corpus suum quod est Ecclesia ut universale salutis sacramentum constituit; sedens ad dexteram Patris continuo operatur in mundo ut homines ad Ecclesiam perducat arctiusque per eam sibi coniungat ac proprio Corpore et Sanguine illos nutriendo gloriosae vitae suae faciat esse participes" (L.G. 48, 2). Y aparece también como expresión de su condición y permanente referencia escatológica: el Concilio presenta a la Iglesia no solo como sacramento de la salvación escatológica, sino también como sacramento escatológico de salvación: "Restitutio ergo quam promissam exspectamus, iam incepit in Christo, provehitur in missione Spiritus Sancti et per Eum pergit in Ecclesia in qua per fidem de sensu quoque vitae nostrae temporalis edocemur, dum opus a Patre nobis in mundo commissum cum spe futurorum bonorum ad finem perducimus et salutem nostram operamur (cf. Phil 2, 12). Iam ergo fines saeculorum ad nos pervenerunt (cf. 1Cor 10,11) et renovatio mundi irrevocabiliter est constituta atque in hoc saeculo reali quodam modo anticipatur: etenim Ecclesia iam in terris vera sanctitate licet imperfecta insignitur" (L.G. 48, 2-3). Sacramentar lo escatológico no solo es una función de la Iglesia sino que primariamente refiere a su misma condición.

(43) En el ejercicio de su mediación sacramental la Iglesia ofrece al mundo su propia relación a Cristo en el Espíritu, que es lo que la constituye en anticipación de la cristofinalización de la humanidad y del mundo, anticipación sacramental de la plenitud "ya comenzada" pero "todavía no" consumada. 


\section{RESULTADOS MÁS IMPORTANTES}

\section{Tres resultados relacionados con la comprensión de la metodología del Concilio}

El primero tiene que ver con el carácter sinodal de la asamblea conciliar. Ello ha permitido reconocer un desarrollo, una importante evolución en relación al tema que nos ocupa. El camino recorrido por la reflexión del Vaticano II tiene como punto de partida afirmaciones que, en el contexto de una noción de Iglesia restringida y parcial, simplemente identificaban Reino e Iglesia. La irrupción de la temática del Reino en su reflexión no solo reflejó una reacción crítica a esta primera identificación, sino que en ella quedó de manifiesto que una correcta comprensión de su relación con el Reino es determinante para una más amplia y rica noción de la Iglesia. Esta relación adquirió rasgos particulares al momento de la inserción en el esquema De Ecclesia del capítulo VII: en él queda determinada por la condición y orientación escatológica de la misma Iglesia y por la orientación eclesiológica de la escatología. Así también, y como ya se ha indicado antes, la comprensión de esta relación se vio enriquecida en el desarrollo de la enseñanza de Gaudium et Spes, Ad Gentes y Apostolicam Actuositatem.

En el contexto de este camino sinodal surgió expresamente la necesidad de dar una base más bíblica a la reflexión del Concilio. La comprensión de esta opción metodológica y la valoración de la misma es lo que quiero señalar como un segundo e importante resultado de esta investigación. La permanente referencia a la Sagrada Escritura constituye un supuesto determinante para la interpretación de las afirmaciones conciliares referidas a la relación del Reino y de la Iglesia. El proceso de intelección que se establece al interior del Nuevo Testamento, determinado por el acontecimiento pascual, constituye una clave de lectura para comprender esta relación y lo que el Concilio dice de la misma (44). La concentración cristológica de la escatología neotestamentaria, la distinción y correspondencia entre Reino de Cristo y de Dios, entre el "ya" y el "todavía no" del evento escatológico, así como la confesión de fe en el Señorío glorioso de Cristo y su comunicación por el Espíritu (45), son nociones también determinantes para esta comprensión.

(44) En L.G. 5 la revelación del Reino sigue los pasos que es posible reconocer en el desarrollo de la tradición al interior del mismo Nuevo Testamento: 1. El anuncio del Reino de Dios como núcleo de la predicación y enseñanza del Jesús histórico; 2. El comienzo de su manifestación en las palabras, en las obras y en la persona del mismo Jesús; 3. Su identificación con la persona misma de Cristo, Hijo de Dios e Hijo del hombre; 4. Su realización primera en el Señorío de Cristo y nuestra participación en él, por el don del Espíritu Santo; 5. La condición y misión de la Iglesia a la luz de su realización actual y de su cumplimiento escatológico.

(45) En L.G. 36, 1 encontramos una buena síntesis de la perspectiva soteriológica de la teología paulina. En este párrafo explícitamente se vincula el Reino con el Señorío de Cristo y, siguiendo la comprensión histórico-salvífica de Pablo, se indican tiempos y ámbitos de su realización: 1. Cristo, habiendo sido exaltado por el Padre (cfr. Fil 2, 8-9), entró en la gloria de su Reino; 2. Su soberanía, que es actual y universal, y que tiene connotaciones antropológicas, eclesiales y cósmicas, crece y se dilata, como victoria y liberación (cfr. Rom 6, 12), hasta el pleno sometimiento a Dios de todas las cosas; 3 . En su fase final o escatológica esta soberanía supondrá el sometimiento de Sí mismo y de todo lo creado al Padre a fin de que Dios sea todo en todas las cosas (cfr. 1 Cor 15, 27-28) y la misma creación sea liberada de la servidumbre de la corrupción para participar en la libertad de la gloria de los hijos de Dios (cfr. Rom 8, 21). 
El mismo Concilio impone leer sus afirmaciones referidas a la relación ReinoIglesia, en confrontación con el conjunto de su enseñanza. Es este un tercer resultado de índole metodológico que me interesa señalar. Las perspectivas más propias del capítulo I y II de Lumen Gentium quedan enriquecidas y ampliadas, por ejemplo, a la luz del capítulo VII de la misma Constitución Dogmática y de los cuatro capítulos de la primera parte de la Constitución pastoral Gaudium et Spes. La verdad es que la enseñanza conciliar referida a la relación del Reino y de la Iglesia solo puede ser comprendida a la luz de las líneas más centrales de su pensamiento teológico: la concepción trinitaria de su eclesiología, las dimensiones universales de la salvación realizada en Cristo y continuada en la misión de la Iglesia, la índole cristocéntrica y escatológica del Reino, de la misma Iglesia y también del mundo, entre otras.

\section{Tres resultados relacionados con la comprensión de algunas opciones teológicas de la reflexión conciliar}

Del uso indiferenciado de las expresiones Reino de Dios y Reino de Cristo, de su intercambiabilidad, es posible colegir, a modo de un primer resultado teológico, una de las aportaciones más notables del Vaticano II: la concentración cristológica de sus enunciados escatológicos. En la línea de la renovación del discurso escatológico (46) el Concilio comprende el misterio de Cristo como el acontecimiento en el cual se realiza en plenitud el designio de salvación de Dios, como cumplimiento de las promesas y recapitulación de toda la historia de la humanidad (G.S. 10, 2; 45, 2). A la luz de la pascua todo el evento de Cristo queda comprendido como acontecimiento escatológico: constituye el punto culminante de la economía de la salvación, la intervención última y definitiva de Dios, que inaugura el tiempo del cumplimiento e introduce la historia humana en una nueva etapa, última y definitiva, encaminada a su plena realización el día de su parusía. Una lectura atenta de L.G. 48, que podemos legítimamente comprender como síntesis de la enseñanza escatológica del Vaticano II, nos permite reconocer la centralidad del evento de Cristo en el discurso escatológico del Concilio. Esta concentración cristológica de la soberanía salvífica de Dios incluye el carácter actual y remoto a la vez del cumplimiento del Reino (P.O. 2,5; G.S. 39,3) y la participación en él de toda la realidad creada (L.G. 36,1; G.S. 39,3).

Como segundo resultado teológico indico la comprensión unitaria de la economía de la salvación que caracteriza la enseñanza del Vaticano II (47). Tal unidad

(46) Esta renovación, a mi entender, así como ha tenido un punto de partida en el redescubrimiento de la índole escatológica del mensaje del Nuevo Testamento ha tenido como punto de llegada una comprensión cristocéntrica de los planteamientos escatológicos bíblicos y dogmáticos. En esto el Concilio se vio favorecido por un trabajo teológico previo que, en el ámbito de la teología católica, quedó sintetizado y, al mismo tiempo, proyectado en dos artículos que marcaron época: el de H. U. VON BALTHASAR, Eschatologie, en J. FEINER-J. TRÜTSCH-F. BÖCKLE (Eds.), Fragen der Theologie heute, Einsiedeln, 1958, pp. 403-422 y el de K. RAHNER, Theologische Prinzipien zur Hermeneutik eschatologischer Aussagen, en íd., Schriften zur Theologie, T. IV, Benziger Verlag, Einsiedeln-Zurich-Köln, 1960, pp. 401-428.

(47) Esta concepción unitaria de la economía de la salvación impone leer en un sentido cristocéntrico y pascual las afirmaciones referidas a la creación, y en un sentido consolidador y recapitulador los misterios de la encarnación y glorificación pascual de Cristo. Cfr. J. M. R. TILLARD, $L a$ Iglesia y los valores terrenos, en G. BARAUNA (Dir.), La Iglesia en el mundo de hoy. Estudios y 
brota precisamente del misterio de Cristo: desde la manifestación de su Señorío pascual, es confesado como el acontecimiento escatológico-salvífico que lleva a su pleno cumplimiento, a través del misterio redentor de su encarnación y pasión, de su resurrección y glorificación, las virtualidades contenidas en su dominio original sobre la creación y la historia. Esta unidad económico-salvífica que vincula íntimamente creación y redención supone y, a la vez, requiere, aquella estrecha solidaridad hombre-cosmos que el Concilio señala expresamente (L.G. 48,1; G.S. 14,1; A.A. 7,2 ). Es a través del hombre como toda la creación y la historia aspiran a participar en la gloriosa libertad de los hijos de Dios y, a través de la humanidad de Cristo, perfecta en su encarnación y glorificada en su resurrección, el mismo hombre y todas las cosas alcanzan dicha libertad. Lo que en Cristo se ha cumplido, Él mismo lo ha ganado para todo hombre y el universo entero (L.G. 48).

A partir de esta comprensión unitaria de los misterios de la creación y de la redención, el número 7 de Lumen Gentium, especialmente en su cuarto párrafo, comprende la relación de Cristo con la Iglesia en el contexto del designio eterno y universal de someter todas las cosas a Cristo, primogénito de toda la creación y primogénito de entre los muertos. Designio eterno y escatológico cumplido ya en Cristo muerto y resucitado como Cabeza de las potencias cósmicas y Cabeza de la Iglesia, el cual ejerce actualmente su poder, en forma de victoria y dominio sobre los poderes rectores de este mundo y como fuente de vida de la Iglesia, en orden a la reconciliación en Él de todo el universo. Se trata de dos dimensiones del único acto redentor de Cristo, del cual ya es posible participar en el presente en vistas de su cumplimiento escatológico. Ahora bien, y como expresión de esta misma unidad de la economía de la salvación, la capitalidad de Cristo que se refiere a todo el universo se focaliza en la Iglesia (48). La

comentarios a la constitución 'Gaudium et Spes' del Concilio Vaticano II (Esquema XIII), Studium ediciones, Madrid, 1967, pp. 247-286; M.-D. CHENU, La misión de la Iglesia en el mundo contemporáneo, en íd., pp. 379-399; J. ALFARO, Cristología y Antropología. Temas teológicos actuales, Ediciones Cristiandad, Madrid, 1973, especialmente capítulo III: Cristología y Eclesiología en el Concilio Vaticano II, pp. 105-120; A. ARTEAGA, Creatio ex Amore. Hacia una consideración teológica del misterio de la creación en el Concilio Vaticano II, Anales de la Facultad de Teología, vol. XLVI (1995), cuaderno 1, Pontificia Universidad Católica de Chile, Santiago, 1995, especialmente capítulo VI: Las dimensiones de la doctrina conciliar. Aproximación sistemática, pp. 93-102.

(48) Es de la mayor importancia comprender a la luz de la capitalidad de Cristo la vinculación entre la Iglesia y el cosmos. Como lo señala adecuadamente R. SCHNACKENBURG no pueden existir el reino de Cristo sobre el mundo y simultáneamente sobre la Iglesia sin tener alguna vinculación o roce. Luego de mencionar los principales textos en los que se establece un ensamblaje de las afirmaciones cósmicas y eclesiológicas, a saber Col 1, 15-20; Ef 1, 21-24; 4, 8-16, afirma: "Así habrá que decir que el reino de Cristo se realiza sobre el mundo de una manera peculiar en la Iglesia, condensada como una eficiencia llena de gracia. En la Iglesia se sustrae a los "poderes" su campo cósmico de acción; del mismo modo que la Iglesia va edificándose a partir de su celestial Cabeza, del mismo modo va reduciéndose el poder de estas potencias en el cosmos. Con la Iglesia va Cristo incorporando progresivamente el reino al universo, sobre todas las cosas y lo va sometiendo cada vez más vigorosa y perfectamente bajo Él mismo que es la Cabeza. Ciertamente que esto no identifica la Iglesia y el cosmos, pero la Iglesia adquiere una importancia cósmica. Iglesia y cosmos no se hallan el uno frente a la otra como dos planos separados que solo tienen de común a Cristo glorificado, sino que el cosmos es abarcado por Cristo en la Iglesia y a través de la Iglesia, conquistado o sojuzgado" (R. SCHNACKENBURG, Reino y reinado de Dios.

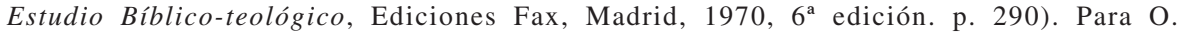
CULLMANN la Iglesia es el centro del Reino de Cristo ya que ha sido escogida para ser el lugar terrestre del Cuerpo de Cristo y lo es además por ser la comunidad humana hacia la cual, desde 
Iglesia es la realidad que encarna en la historia el designio eterno de Dios revelado y cumplido en Cristo: designio de reconciliación y unidad que incluye a todo el universo. La Iglesia, comprendida como cuerpo de Cristo, expresa en la historia la vocación a la unidad escatológica de todo lo creado. Más aún, es posible decir que en la capitalidad actual sobre la Iglesia se va realizando la capitalidad sobre el cosmos: la unidad y reconciliación, cumplida y revelada en Cristo muerto y resucitado, por la acción del Espíritu Santo, se va realizando históricamente en la Iglesia, la que, en la medida en que reúne a judíos y gentiles, constituye una anticipación de la reconciliación cósmico-escatológica (cfr. Ef 2, 13-18).

Entiendo que esta misma comprensión unitaria de la economía de la salvación es la base teológica de la metodología propia de Gaudium et Spes. Partiendo de la antropología, la cristología constituye el criterio y la perspectiva permanente para comprender sus enunciados antropológicos (49). Así procede la Constitución pastoral en su primera parte: luego de señalar en su exposición introductiva la situación actual del hombre y sus interrogantes, plantea que Cristo es la respuesta (G.S. 10,2), y presenta el misterio de Cristo, al final de cada capítulo antropológico, como aquel en el cual se encuentra la fuente y la plenitud de la perfección humana (G.S. 22; 32; 38; y también el 45): El que es imagen del Dios invisible y primogénito de la

sus orígenes, tiende el plan divino de la redención. Respecto de lo primero afirma que "la Iglesia es, en cuanto lugar, el centro, el punto vital del reino de Cristo. No es solamente una suya, sino el punto único en el que se manifiesta visiblemente todo el reinado de Cristo, y cuanto en él ocurre influye de manera decisiva en el reino de Cristo... Esta posición central de la Iglesia en el reino de Cristo la expresa el Nuevo Testamento designando a la Iglesia como el cuerpo de Cristo... La Iglesia en cuanto lugar es realmente una parte de todo el campo en el que reina Cristo y del cual es Él la cabeza; mas, por otra, Cristo mismo está presente en esta parte limitada de su reino de una manera muy distinta que en las demás" (O. CULLMANN, La realeza de Cristo y la iglesia. Según el Nuevo Testamento, Studium ediciones, Madrid, 1974, pp. 53-55). Respecto de lo segundo afirma que desde el principio todo tiende hacia la Iglesia, la cual cumple en el entero plan de la redención una función de sustitución: "Así como la caída del primer hombre tuvo consecuencias decisivas para la creación entera, también la existencia de la comunidad humana de la Iglesia es desde ahora decisiva para la creación, recapitulada en el reino de Cristo. Como hombre entre los hombres, y en este mundo visible, es como Cristo en su encarnación histórica ha obrado, sufrido y muerto en la cruz; sin embargo, con esa acción histórica, terrena y humanamente limitada ha vencido a las potencias y dominaciones invisibles; de la misma manera la acción del cuerpo de Cristo - la Iglesia de los que creen en su redención por la muerte de Cristo- actúa en el mundo de las realidades celestes 'para que la multiforme sabiduría de Dios sea ahora notificada por la Iglesia a los principados y potestades en los cielos' (Ef 3, 10), esa sabiduría de la cual se dice en 1 Cor 2, 8, que los 'principes de este siglo' no la conocieron 'al crucificar al Señor de la gloria'... Aunque la Iglesia no ejerce su acción más que entre los hombres -excepto en ese acto final que tendrá lugar en el eón futuro-, todo su proceder, sin embargo, es de la mayor trascendencia para el reino de Cristo" (Ibídem, pp. 72-73).

(49) Confrontar L. F. LADARIA, El hombre a la luz de Cristo en el Concilio Vaticano II, en R. LATOURELLE (Ed.), Vaticano II. Balance y perspectivas, Ediciones Sígueme, Salamanca, 1989, pp. 705-714; W. KASPER, La antropología teológica de la Gaudium et Spes, en Laicos Hoy, 3 (1996), pp. 45-55; L. GERA, La correlación entre la cristología y la antropología en la Constitución pastoral Gaudium et Spes, en J. C. MACCARONE, La Constitución Gaudium et Spes. A los treinta años de su promulgación, San Pablo, Buenos Aires, 1995, pp. 145-190; A. BENTUÉ, La Constitución sobre la Iglesia en el mundo actual (Gaudium et Spes), en Teología y Vida XXXVII (1996), pp. 113-128; G. RESTREPO, La antropología en la "Gaudium et Spes”, en Teología y Vida XXXVI (1995), pp. 279-290. Cfr. también J. L. RUIZ DE LA PEÑA, Imagen de Dios. Antropología teológica fundamental, Sal Terrae, Santander, 1988, especialmente capítulos IV-V. 
creación, como Verbo encarnado, hombre perfecto, realiza a plenitud la vocación de todo hombre y, devolviendo al hombre, en el misterio de su pascua, la semejanza divina deformada por el pecado, se establece como medio para que todos puedan alcanzar en Él su plenitud. Desde Cristo surge una valoración positiva del hombre y su historia y una justa comprensión de su autonomía. Más aún, Cristo, Verbo encarnado, en su humanidad divinizada perfecciona y eleva al hombre y su historia y, en el misterio de su pascua, abre lo humano a una plenitud escatológica en la cual queda confirmado y perfeccionado el misterio del hombre, liberado del enigma del dolor y de la muerte, y de la desesperación inherente $(22,6)$.

Como tercer resultado referido a las opciones teológicas del Concilio puedo indicar algunas características del Reino que se desprenden de su enseñanza. La expresión in mysterio (50) perfila el estar presente del Reino en aquellas afirmaciones que más radicalmente indican su presencia actual en el mundo: L.G. 3 y G.S. 39. En ellas remite en lo inmediato a un "estar presente en crecimiento" en vistas a un futuro cumplimiento pleno del mismo (51). El in mysterio señala una referencia escatológica permanente de cualquier actualización del Reino, ya en la Iglesia ya en el mundo, que impide una realización acabada del mismo en la historia (52); lo que

(50) La expresión bíblica mysterium refiere al "designio de Dios de realizar la salvación de los hombres por medio de Jesucristo -designio tomado desde el comienzo de los tiempos y oculto, pero revelado ahora en la plenitud de los tiempos-". (G. RICHTER, Misterio I: Sagrada Escritura, en H. FRIES, Conceptos Fundamentales de la Teología, T. II, Ediciones Cristiandad, Madrid, 1979, pp. 65-70). Cfr. también en el mismo volumen el artículo de K. RAHNER, Misterio II: Teología, pp. 70-75. Este autor señala que el misterio determina esencialmente la relación del hombre con Dios, "tal como es experimentada dicha relación dentro del proceso de la existencia cristiana bajo la llamada de la gracia divina" (p. 74). Esta comprensión indica a su vez una perspectiva teológica y antropológica en la noción del misterio. "Dios es misterio porque es la persona absolutamente libre, la única que dispone de sí misma, razón por la cual solo puede ser conocido a través de su conducta, en la cual realiza y manifiesta su ser mismo, tal como se revela en la experiencia de tipo histórico, siempre sorprendente e inasequible desde cualquier otro punto" (p. 71). Lo es en cuanto es la plenitud infinita del ser, una plenitud que el hombre no puede alcanzar. Desde esta comprensión, el misterio tiene una relación originaria al ser conjunto del hombre en todas sus dimensiones. La persona finita hecha de espíritu y libertad es el ser del misterio y para el misterio: la razón no debe concebirse como la capacidad de eliminar el misterio mediante la penetración racional, sino como la capacidad de asumirlo en el amor. Así, también, el misterio no cesa cuando el hombre logra en virtud de la gracia la consumación prometida: sino que entonces se impone definitiva e ineludiblemente.

(51) En ambos textos, en el que refiere a la presencia del Reino de Cristo como Iglesia (L.G. 3) y en el que remite la presencia actual del Reino a los frutos de la naturaleza y de la libertad humana (G.S. 39, 3), se contextualiza esta presencia en su referencia a un futuro cumplimiento pleno de la misma. Así está señalado en el texto de Lumen Gentium que afirma expresamente una dinámica de crecimiento, de crecimiento visible en el mundo, por el poder de Dios ("ex virtute Dei"). Así también en el texto de Gaudium et Spes en el que la afirmación de la presencia actual del Reino queda contrastada con la consumación de su perfección en el día de la venida gloriosa de Cristo ("adveniente autem Domino consummabitur").

(52) En este sentido sería también aplicable a la Iglesia la expresión "reserva escatológica". Esta expresión, nacida en el contexto del programa de teología política de J. B. METZ, señala el carácter dialéctico de la relación entre el futuro de la promesa y la realidad histórica. Entre ambos se establece una relación crítico-constructiva que, por una parte, impide toda pretensión totalizante de cualquier sujeto intrahistórico (ya que el futuro prometido no se identifica con ninguna realización intramundana), y, por otra, libera y estimula a una constante renovación de las relaciones sociales, queriendo verificar en ellas, a través de una ética política, la esperanza en las promesas escatológicas. Cfr. J. B. METZ, Teología del Mundo, Ediciones Sígueme, 
está visualizado precisamente en la dinámica del crecimiento. Ahora bien, la perspectiva del crecimiento alude a una dimensión más profunda del in mysterio de la presencia del Reino: a su condición de realidad oculta.

La referencia al futuro es una primera dimensión del carácter oculto de la presencia actual del Reino (53). La irrupción en la historia del Reino de los cielos y su presencia actual en la Iglesia y en el mundo es anticipo de una plenitud que solo advendrá en el futuro. La futuridad del Reino queda confirmada precisamente con la afirmación de una actualidad en tensión a su cumplimiento pleno, presencia actual que solo puede ser comprendida como comienzo germinal. El futuro del Reino se comporta como novedad, contenida pero no manifiesta, prometida pero no develada, anunciada, presentida, pero no realizada aún.

Como segunda dimensión del carácter oculto de la presencia del Reino el Concilio señala su referencia a la totalidad de la creación, su universalidad (54). Esta característica propia del futuro del Reino, del tiempo de su cumplimiento pleno, se manifiesta como tal también en el tiempo de su irrupción e inauguración en la historia: en la Iglesia y en el mundo, a la luz del Señorío de Cristo, se da una presencia anticipada del Reino eterno y universal. Esta presencia actual, focalizada en la Iglesia y contenida en los frutos buenos de la naturaleza y de nuestros esfuerzos, pulsa más allá de sí misma, en cuanto está llamada a dilatarse hasta abarcar toda la realidad.

Por último, la teologicidad del Reino es la razón más alta de su carácter oculto. Lo que se explicita no solo en el modo trinitario de su irrupción y crecimiento en el mundo (55), sino también y sobre todo en su íntima vinculación con el querer

Salamanca, 1970, especialmente capítulos 3 y 5; cfr. también J. NOEMI, El mundo creación y promesa de Dios, San Pablo, Santiago, 1996, pp. 243-244; G. GRESHAKE, Escatología e historia, en Selecciones de Teología 13 (1974), pp. 195-196; J. J. TAMAYO, Utopías históricas y esperanza cristiana, en C. FLORISTAN-J. J. TAMAYO, El Vaticano II, veinte años después, Ediciones Cristiandad, Madrid, 1985, pp. 315-318; y en un sentido crítico G. ANGELINI, El desarrollo de la teología católica en el siglo XX, en Diccionario Teológico Interdisciplinar IV, Ediciones Sígueme, Salamanca, 1983, pp. 807-811.

(53) En el número 9 de Lumen Gentium se afirma claramente la dualidad histórico-temporal que caracteriza la presencia del Reino en la historia humana: incoado por el mismo Dios en la tierra, está llamado a crecer, hasta que el mismo Dios lo consume al final de los tiempos, cuando Cristo se manifieste y la misma creatura sea liberada de la servidumbre de la corrupción para participar en la libertad de los hijos de Dios. La realización futura del Reino ya ha comenzado con la glorificación de Cristo (L.G. 36, 1), y se consumará su perfección el día de su manifestación gloriosa, cuando a Él queden sometidas todas las cosas y Él entregue al Padre el Reino eterno y universal (L.G. 36, 1; G.S. 39, 3; P.O. 2, 5). El futuro del Reino o, mejor dicho, el futuro de todo lo creado en él, está ampliamente atestiguado en los textos del Vaticano II: se dice que la misma creación está llamada a participar, en el Reino del Señor, de la gloria de los hijos de Dios (L.G. 36, 1); que todos estamos llamados a reinar con Cristo (L.G. 48, 4); que la comunidad de los discípulos de Cristo peregrina hacia el Reino del Padre (G.S. 1); que la Iglesia, al tiempo de la segunda venida del Señor, será recogida como mies en el Reino de Dios (A.G. 9, 1).

(54) La acción favorable de Dios tiene como referente la creación entera. Es toda ella la llamada a participar de la gloriosa vida divina (L.G. 9, 2; 36, 1). Sostenida en el amor de Dios creador, animada constantemente por su presencia salvadora, la creación llegará un día a participar de la misma vida divina, cuando se convierta en "reino de la verdad y de la vida, de la santidad y de la gracia, del amor, la justicia y la paz" (L.G. 36, 1; G.S. 39, 3).

(55) En los dos textos a los cuales hacemos referencia en esta sección está señaladamente afirmado e modo trinitario de la irrupción y crecimiento del Reino: En L.G. 3 el Hijo enviado por el Padre inauguró en la tierra el Reino de los cielos; el Reino de Cristo presente actualmente en misterio 
salvífico de Dios que encamina el mundo y su historia a la plena participación en la vida divina. El Reino se identifica con esta voluntad de salvación, y el pleno cumplimiento de la misma constituirá su realización acabada como plenitud de la historia (56). En la actual fase de la economía de la salvación la presencia del Reino dinamiza toda la realidad haciéndola participar ya de esta meta última, que constituye, a su vez, el fundamento de toda las cosas.

\section{Tres resultados referidos al contenido mismo de esta investigación}

El principal resultado es el reconocimiento de que en el Concilio concurren al menos dos líneas de pensamiento escatológico, complementarias e irreducibles. Una primera línea, centrada en la imagen del Reino, surge en el transcurso de los debates en torno a Lumen Gentium: allí se propone como contexto mayor a la luz del cuál queda mejor comprendido el ser y quehacer de la Iglesia. Una segunda línea la constituye la escatología de la Iglesia, la cual queda sancionada al momento de la incorporación del capítulo VII en el texto de la Constitución dogmática sobre la Iglesia: la definición de la Iglesia una en tres estados de desarrollo, celeste, purificante y peregrina, es también determinante para la correcta comprensión de las afirmaciones escatológicas del Vaticano II. Ambas líneas de pensamiento se anudan en la enseñanza del Concilio: están presentes en sus diversos documentos y en aquellas afirmaciones que hemos reconocido como directamente referidas a la relación del Reino y de la Iglesia.

La confluencia de ambos tipos de pensamiento se produce armónicamente en torno a dos núcleos articuladores de la enseñanza del Concilio: la confesión de fe en

crece visiblemente en el mundo por el poder de Dios. En G.S. 39 tanto la presencia actual del Reino (presente en los frutos de la naturaleza y de nuestro esfuerzo en cuanto propagados en el Espíritu del Señor y conforme a su mandato), como su realización futura (será consumado cuando Cristo entregue al Padre el Reino eterno y universal) son obra del Dios trino.

(56) El Reino hunde sus raíces en la Trinidad, es la manifestación en la historia del misterio eterno del amor salvífico de Dios Padre, Hijo y Espíritu Santo. Los primeros números de la constitución Lumen Gentium orientan la enseñanza del Concilio en esta dirección. En ellos, especialmente en el número 3, aparece la revelación de la voluntad salvífica de Dios en la imagen del Reino, obra del Padre, del Hijo y también del Espíritu. La expresión "Reino de los cielos" parece contener el misterio del designio eterno creador y salvador, que Cristo ha inaugurado y manifestado en el mundo. La expresión "Reino de Cristo", equivalente en este número a "Iglesia", parece expresar la presencia también mistérica, aunque visible y dinámica, de este designio en la historia de los hombres. Sin utilizar la expresión Reino, el número 4 de Lumen Gentium alude a la obra del Espíritu en su acción santificadora en la Iglesia y en los creyentes. Continuador de la obra del Hijo, el Espíritu aparece como el agente escatológico del misterio salvador de Dios.

Entonces el Reino es expresión de la acción trinitaria en favor de una creación orientada a su pleno cumplimiento en Dios. El Reino es siempre acción de Dios, aun en su fase históricoterrena. Es Dios mismo quien lo inaugura, lo hace crecer, lo lleva a su plenitud (L.G. 9, 2). Cristo y el Espíritu, enviados por el Padre, son los agentes que animan su instauración y crecimiento en el mundo (L.G. 3-4; S.C. 6; G.S. 38, 1). Aun cuando el Reino, en su realidad histórica y terrena, aparezca muy unido a la Iglesia, casi dependiente de su misión, es una realidad que escapa al querer y poder meramente humanos (A.G. 42, 2).

Asimismo, el Reino constituye la meta hacia la cual está orientada toda la realidad: expresa la comunión en la vida trinitaria a la cual, por impulso del mismo Dios, se encamina el hombre, la historia y la misma creación (G.S. 1). El fin de la historia es la entrada de toda la realidad en la misma vida divina, cuando Cristo entregue a Dios Padre el Reino eterno y universal (G.S. 39, 3; P.O. 2, 5). 
el Señorío de Cristo resucitado y glorificado y la comprensión del hombre en su condición de agraciado y llamado a la comunión divina. A su luz Reino e Iglesia quedan señalados en su propia riqueza de significado y en su recíproca relatividad y complementariedad. A la luz del Señorío de Cristo el Reino queda comprendido como realidad decisiva y dinámicamente presente en la historia del mundo, a la vez que futuro ya comenzado de la misma. La Iglesia se visualiza como expresión del irrumpir de este Señorío, concreción histórica del mismo, al tiempo que llamada a crecer hasta su cumplimiento pleno, del que ya participa anticipadamente y al que porta en medio del devenir de la humanidad. A la luz del mundo, en el que irrumpe de la mano del Señorío de Cristo, el Reino queda señalado en su esencial eclesialidad, en su condición de futuro omniabarcante del mismo, al que adviene mistérica y sacramentalmente. La Iglesia, a la luz del mundo, queda comprendida como futuro anticipado de la humanidad, junto a la que camina históricamente y a la que sirve sacramentalmente, desde su participación inicial, también mistérica, en la plenitud escatológica.

De la integración armónica de estas dos líneas de pensamiento escatológico derivan importantes consecuencias teológicas y pastorales, mediadas por una correcta comprensión de la relación Reino e Iglesia. Al definir la relación entre ambas entidades queda claro que no se pueden separar, a riesgo de sesgar la comprensión de las mismas. El mismo riesgo asoma en el intento de identificarlas sin más. La escatología del Reino engloba a la de la Iglesia, la que se despliega al interior de un movimiento mayor y más amplio, y al que remite constantemente. Este movimiento mayor y más amplio es el designio de Dios de conducir todas las cosas a participar de la vida divina, expresado totalmente en la imagen del Reino. El Reino es la misma capitalidad de Cristo de la cual la Iglesia proviene histórica y existencialmente y a la que conduce, como futuro último, expresándola en el tiempo, anticipándola, haciéndola presente y constituyendo desde ya la textura de su cumplimiento escatológico. No son lo mismo, sin embargo así como la Iglesia no puede separarse del Reino al que sirve, así tampoco el Reino puede separarse de la Iglesia en la que está sacramentado. Diversidad y, al mismo tiempo, inseparabilidad, parece ser la justa comprensión de la relación entre ambas realidades, que el Concilio asume y aporta a la teología.

Un segundo resultado, no menos importante, dice relación con la comprensión de la mundanidad del Reino y, a su luz, con la comprensión de la insoslayable realidad mundana de la misma Iglesia. La clave cristológica de la teología del Concilio lo impone, y la antropología cristológica de Gaudium et Spes lo desarrolla. El "his in terris Regnum iam in mysterio adest" (G.S. 39,3) viene a ser la culminación de este desarrollo, ya que se articula como conclusión de los capítulos antropológicos inmediatamente anteriores y, a la vez, da paso al capítulo IV de la primera parte de la Constitución pastoral que trata de la Iglesia, la que existe en el mundo, y con él vive y actúa.

El reino adviene allí donde Dios, en Cristo y por la virtud del Espíritu, es acogido en la comunicación de su amor, que confirma, restituye y eleva nuestra dignidad, nuestra apertura comunional y nuestra libertad, al permitirnos vivir el mandamiento nuevo del amor, que es la ley fundamental de la perfección humana y de la transformación del mundo (cfr. G.S. 38,1). Este es también el origen histórico y existencial de la Iglesia, a la vez que su deber ser y su futuro: ella está formada 
por hombres que, reunidos en Cristo, son guiados por el Espíritu Santo en su peregrinación hacia el Reino del Padre (G.S. 1; cfr. 40,2). A la luz del Reino la existencia de la Iglesia adquiere contextura humana: se halla siempre en gestación y en permanente conquista como la vida del mismo hombre en la historia. A partir de la síntesis de lo histórico y lo escatológico contenida en la comprensión de la condición peregrina de la Iglesia, el Concilio caracteriza con rasgos antropológicos a la misma Iglesia: como comunidad que camina en la esperanza, realidad in fieri, que experimenta en su existencia y misión la condición de precariedad, que sufre en sus miembros la tentación del pecado, llamada a crecer en santidad, necesitada de purificación y renovación continua, y en todo ello fortalecida con la virtud del Señor Resucitado (cfr. L.G. 6,5; 8,3-4; 9,3; 48,3; G.S. 40,2; A.G. 5,2).

El reino se hace presente y visible, a modo de anticipación, en aquellos gérmenes de comunión y fraternidad que el mismo Cristo, por su Espíritu, suscita en la historia, haciendo así crecer en ella el "cuerpo de la nueva familia humana" (39,2). En este contexto, la Iglesia, en razón de su pertenencia absoluta a Cristo, de quien es cuerpo y esposa, constituye un fruto anticipado de la comunión del Reino, espacio en el que comienza a verificarse y órgano a través del cual Cristo mismo establece misteriosamente su soberanía en el mundo. Es por esto que, si bien la Iglesia participa en su condición histórica de la provisionalidad que caracteriza toda presencia del Reino en la tierra, sin embargo le corresponde una tarea crítico-constructiva respecto del mundo: al señalarle su consistencia y destino escatológicos le aporta un criterio de discernimiento que impide, a cualquier realización histórica, la pretensión de proponerse como lo definitivo, al tiempo que le hace consciente que, siendo el futuro escatológico una realidad ya comenzada y abierta, es también anticipado y preparado en la historia y está precontenido en todos aquellos signos de comunión y fraternidad que ya se dan en el presente. Ahora bien, esta tarea crítico-constructiva revierte sobre la misma Iglesia: la comunión que señala presente o que denuncia ausente en el caminar de la humanidad la interpela permanentemente y le impone a ella misma crecer, desde el Reino y hacia el Reino, por los caminos de una siempre mayor comunión y fraternidad.

Como tercer resultado se impone aludir a la dimensión sacramental de la presencia del Reino en la historia y de su relación con la Iglesia. Es de notar que el Concilio nunca habla de la Iglesia como sacramento del Reino. Partimos entonces de la sacramentalidad del Reino: en la encarnación del Hijo de Dios la comunicación de la gracia asume la realidad creada y la historia humana; de ello deriva la posibilidad de significación e instrumentalidad de las realidades humanas en orden a la comunicación de la vida divina y de la salvación de los hombres, al tiempo que funda la condición sacramental de la misma Iglesia. La sacramentalidad de la Iglesia es analógica por deficiencia respecto de Cristo: trasmite el contenido del amor de Dios en toda su plenitud, pero de modo imperfecto debido a su figura finita, humana y pecadora; y es analógica por eminencia respecto de sus acciones sacramentales y de otras presencializaciones simbólico-reales del advenir del Reino: la Iglesia manifiesta ya la unidad definitiva del Pueblo escogido de Dios, ella es la forma terrena de la salvación, el comienzo germinal en la tierra del Reino definitivo de Dios. La Iglesia es un "pedazo" del futuro enquistado en el presente histórico del mundo. Su condición y capacidad sacramental tiene una razón escatológica: su configuración con Cristo y la vivificación del Espíritu. 


\section{LÍMITES DE LAS AFIRMACIONES CONCILIARES Y PERSPECTIVAS ABIERTAS}

1. La metodología sinodal propia del acontecimiento y del magisterio conciliar, y que según mi parecer en el Vaticano II se ha verificado de modo eminente, ha impedido una presentación más afinada de la problemática que nos ocupa. Su presencia en el texto de los documentos del Concilio fue fruto de un proceso de incorporación paulatino y trabajoso, del cual se fueron desprendiendo diversas conclusiones. Fue surgiendo al ritmo de los trabajos realizados en torno a la elaboración de cada documento. En lo inmediato, no estuvo presidido por una visión de conjunto o síntesis previa que fuera determinando el modo de su inserción en los diferentes esquemas.

2. Es tal vez por eso que en el Concilio no encontramos una presentación sistemática y acabada de la temática del Reino: ni siquiera el número 5 de Lumen Gentium puede ser considerado como tal. En razón de esto la reflexión sobre el Reino y su relación con la Iglesia carece, en lo inmediato y expresamente indicado, de un horizonte más amplio en el que se pueda contextualizar y a partir del cual definir con más claridad. Será más tarde la Encíclica Redemptoris Missio la que, a nivel del magisterio, y retomando la enseñanza del Vaticano II, desarrollará, en su segundo capítulo, desde una presentación más acabada de la cuestión del Reino las perspectivas de su relación con la Iglesia.

3. Es posible decir que en el Concilio se da una cierta timidez respecto del reconocimiento de una presencia del Reino más allá de las fronteras de la Iglesia visible: nunca lo afirma expresamente. Igual timidez asoma también al momento de vincular la sacramentalidad de la Iglesia con el Reino: como ya lo hemos indicado antes, tampoco el Concilio habla de la Iglesia como sacramento del Reino. En ambos casos se trata de una timidez que impide concluir expresamente unas perspectivas y un desarrollo contenidos en la concentración cristológica, y en sus implicancias antropológicas y cósmicas, de la enseñanza del Vaticano II respecto del Reino, y también de la Iglesia. La encíclica antes aludida afirma con claridad que la realidad incipiente del Reino, siempre en coordinación con el reino de Cristo presente en la Iglesia y en tensión hacia la plenitud escatológica, puede hallarse también fuera de los confines de la Iglesia, en la humanidad entera, siempre que esta viva los "valores evangélicos" y esté abierta a la acción del Espíritu que sopla donde y como quiere (cfr. R.M. 18) (57). Por otra parte, esta misma encíclica, que tampoco

(57) En continuidad con estas afirmaciones de Redemptoris Missio, la más reciente declaración Dominus Iesus, que plantea como legítima la existencia de diversas explicaciones teológicas para las expresiones Reino de Dios, Reino de Dios y de Cristo y para la problemática de su relación con la Iglesia, siempre que ellas no nieguen o vacíen de contenido "en modo alguno la íntima conexión entre Cristo, el Reino y la Iglesia" (número 18), sostiene expresamente: “Afirmar la relación indivisible que existe entre la Iglesia y el Reino no implica olvidar que el Reino de Dios -si bien considerado en su fase histórica- no se identifica con la Iglesia en su realidad visible y social. En efecto, no se debe excluir 'la obra de Cristo y del Espíritu Santo fuera de los confines visibles de la Iglesia'. Por lo tanto, se debe también tener en cuenta que 'el reino interesa a todos: a las personas, a la sociedad, al mundo entero. Trabajar por el Reino quiere decir reconocer y favorecer el dinamismo divino, que está presente en la historia humana y la transforma. Construir el Reino significa trabajar por la liberación del mal en todas sus formas. En resumen, el Reino de Dios es la manifestación y la realización de su designio de salvación en toda su plenitud" (número 19). 
habla de la Iglesia como "sacramento del Reino", ofrece sí una definición del Reino con palabras que recuerdan el contenido de la primera y programática definición de la Iglesia como sacramento, que encontramos en el Vaticano II: la naturaleza del Reino es la comunión de todos los seres humanos entre sí y con Dios (R.M. 15).

4. Hay que decir también que, si bien el Concilio ayuda a mirar y comprender el Reino y su relación con la Iglesia en referencia a distintos ámbitos, hay algunos dentro del mismo Concilio, respecto de los cuales esta línea rectora de la teología del Vaticano II no parece jugar explícitamente un rol determinante. Llama poderosamente la atención la ausencia de la temática en la declaración Nostrae Aetate, dedicada como sabemos a las relaciones de la Iglesia con las religiones no cristianas; más aún si es en el contexto de dichas relaciones donde actualmente se requiere perfilar con más precisión la cuestión del Reino y la de su relación con la Iglesia.

5. Finalmente, en razón de su calidad de "quaestio disputata", el Concilio deja abierta una importante perspectiva contenida en la problemática de la Relación del Reino con la Iglesia: el estatuto de la misma en el cumplimiento escatológico del Reino. Aunque la lógica del discurso conciliar pudiera orientar en el sentido de afirmar una permanencia de la Iglesia como textura y sacramento del cumplimiento escatológico, el Concilio omite una afirmación explícita al respecto.

En la investigación realizada se ha querido ver la cuestión del Reino y la Iglesia partiendo de la relación que el Concilio establece entre ambos. En el transcurso de la investigación, y de acuerdo con el método empleado, se ha visto la necesidad de relacionar primero ambas entidades con otros dos referentes originarios de la enseñanza del Vaticano II: Cristo y el mundo, y su mutua relación. Es desde estas relaciones primarias desde donde ha podido comprenderse más adecuadamente el estatuto del Reino y de la Iglesia y, a partir de ello, atisbar su importante y compleja relación.

\section{RESUMEN}

Este artículo es el resultado de una investigación que ha pretendido leer e interpretar las principales afirmaciones del Concilio Vaticano II que se refieren al Reino y su relación con la Iglesia. Se parte de la constatación de que, si bien la asunción de la categoría Reino tiene una abundante presencia en los documentos del Concilio y es una clave importante de su enseñanza, la comprensión de la misma respecto del nexo que vincula el Reino con la Iglesia no ha sido unívoca, sino que ha dado pie a diversas y contradictorias interpretaciones. En vistas de tales constataciones se ha querido hacer una lectura e interpretación que tiene como soporte al concilio mismo: el conjunto de sus documentos, la recepción que han tenido en la diversa interpretación teológica sus afirmaciones referidas a la relación del Reino y de la Iglesia, la génesis histórica que estas afirmaciones han vivido al interior de su desarrollo sinodal y la confrontación de las mismas con grandes líneas de su pensamiento teológico: su cristología y su antropología. El Concilio establece una relación compleja entre Reino e Iglesia, que hay que decir de muchas maneras, pues determina y refleja la amplitud de su eclesiología.

\section{ABSTRACT}

This article is the result of a piece of research which read and interpreted the main pronouncements of the Vatican Council II concerning the Kingdom and its relation with the Church. It tarts from the assumption that the notion of Kingdom is pervasive in the documents of 
the Council and that its understanding is crucial in her teachings. The link between the kingdom and the church has not been univocal, but has given place to numerous and even contradictory interpretations. Hence, the author offers a new reading and interpretation of the council. $\mathrm{He}$ considers the full set of documents, their reception by different theological interpretations regarding the relation between Kingdom and Church, the historical genesis of the transformations they have been subject to, and their confrontation with the great lines of theological thought: their christology and anthropology. The council establishes a complex relation between reign and Chuch, which needs to be presented in many different ways, as it determines and reflects the Church's amplitude. 